\title{
That Was Then, This Is Now:
}

Replacing the Mobile-Optimized

Site with Responsive Design

Hannah

Gascho Rempel

and Laurie Bridges

\begin{abstract}
As mobile technologies continue to evolve, libraries seek sustainable ways to keep up with these changes and to best serve our users. Previous library mobile usability research has examined tasks users predict they might be likely to perform, but little is known about what users actually do on a mobile-optimized library site. This research used a combination of survey method and web analytics to examine what tasks users actually carry out on a library mobile site. The results indicate that users perform an array of passive and active tasks and do not want content choices to be limited on mobile devices. Responsive design is described as a long-term solution for addressing both designers' and users' needs.
\end{abstract}

\section{INTRODUCTION}

Technology is in a constant state of flux. As librarians well know, emerging technology can quickly become outdated in a few short years. In 2010 Blackberry phones were at their peak, but now their mobile devices account for a little more than 5 percent of the market share and the Android dominates the top spot, with approximately 52 percent of the market share. ${ }^{1}$ As smartphone use and design has continued to proliferate and advance, users have become accustomed to quicker load times for webpages and are now well-acquainted with how to navigate the web from their phones. As the mobile phone market changes and evolves, usability experts continuously update, test, and revise standards for the mobile web.

At Oregon State University (OSU) we recently set out to improve our mobile site. This required updating our knowledge about patron use of library mobile sites, both through reviewing the literature and by conducting our own primary research. What we found surprised us and challenged us to reconsider what we had previously assumed about patrons' mobile habits. In this article we will describe past research on library mobile website usability, our own research on how our mobile library site is used, and why we ended up deciding to use responsive design as the guiding principle for our redesign.

Hannah Gascho Rempel (hannah.rempel@oregonstate.edu), is Science Librarian and Graduate Student Services Coordinator, Oregon State University, Corvallis, Oregon.

Laurie Bridges (laurie.bridges@oregonstate.edu), a LITA member, is Instruction and Emerging Services Librarian, Oregon State University, Corvallis, Oregon. 


\section{Background: That was Then}

In early 2010 we co-authored an article with our then-programmer about the mobile landscape in libraries. We were among the first to propose that libraries should develop separate websites and catalog interfaces optimized for mobile devices. ${ }^{2}$ Based on the widespread implementation of mobile-optimized library websites since then, it appears this proposal was both relevant and timely. Our 2010 recommendations were based on usability studies, library reports, and technology trends from 2007 through 2009. Research and literature at the time pointed to the need for considering the mobile context, for example, the "attention span" of mobile users as they search for information on the go. ${ }^{3}$ We noted the advice of Jakob Nielsen, who indicated that "if mobile use is important to your Internet strategy, it's smart to build a dedicated mobile site." Although that particular webpage is no longer available, the essence of Nielsen's thinking can be found in a Mobile Usability Update posted on September 26, 2011, which states, "A dedicated mobile site is a must," in the introductory paragraph. ${ }^{4}$

The iPhone was released in the United States in late 2007, and in 2008 the proliferation of dedicated mobile sites began. In December 2008, our mobile team focused on developing a site for the two most popular device types at the time, "smartphones" and "feature phones." The differences between the two types of phones were numerous and there were drawbacks to the feature phones. However, we felt it was important to have a site that rendered well on feature phones because at that time feature phones dominated the market with only 28 percent of mobile phone users in the United States owning a smartphone. ${ }^{5}$

Our initial site design in 2008 and 2009 focused on our primary users, members of the university community. The first phase of our mobile website, released in March 2009, included static pages like library hours, contact information, frequently asked questions, and directions. ${ }^{6}$ The second phase, released in September 2009, included a mobile catalog interface (designed in-house), a staff directory, and a computer availability map. In February 2010 the site averaged one hundred unique users a day. Mobile site analytics showed that the most viewed pages were computer availability, catalog, and hours.

\section{Background: This is Now}

Recent research and case studies show a shift in the mobile context. A comprehensive study by Alan Aldrich in 2010 examined the mobile websites of large research universities and their libraries in the United States and Canada. Aldrich notes, "Users seem to want access to information just as if they were using a fully web-capable desktop or laptop computer." Aldrich ponders the possibility that patron expectations and desires may be evolving as smartphones begin to dominate the mobile landscape. ${ }^{7}$

In 2011, Jakob Nielsen noted that because most people do not use the web on their feature phones and most companies do not support feature phones in their web design process, he would no longer be testing feature phones in his usability studies. ${ }^{8}$ Our experience matches Nielsen's on this 
point; approximately 10 percent of daily users accessing our library's mobile site came from feature phones in 2010; in 2012, that number had dwindled to less than 1 percent. In 2012, Nielsen began considering the proliferation of mobile devices beyond phones, when he wrote, "High-end sites will need 3 mobile designs to target phones, mid-sized tablets, and big tablets." 9 Note the slight change in the phrase "dedicated mobile site" (from the 2009 Mobile Usability Update) to "mobile designs." Nielsen goes on to suggest responsive design, which we will address in more detail later in this article, as a solution to this design problem.

As we prepared for another redesign of our mobile site, we knew we needed a current snapshot of users and how they actually use the mobile version of the library's website before starting our redesign. This may sound like a simple decision; however, it is a step that the library literature has not documented well. Researchers have focused on what library users predict they might need rather than analyzing their actual behaviors.

\section{Mobile Site User Experiences}

Mobile library website development has been influenced by other, nonlibrary mobile sites that have placed heavy emphasis on developing sites for users who are on the go. ${ }^{10}$ Earlier studies examining general mobile browsing and searching habits found that mobile users' most popular activities were reading news, weather, or sports articles, looking for information using search engines, and checking email. ${ }^{11}$ When libraries used these studies to inform mobile site development, the result was a streamlined version of the full library site. It is instructive to consider studies like those done by Coursaris and Kim, who performed a meta-analysis of more than one hundred mobile usability studies. They demonstrated both the extreme breadth of mobile usability research, which has examined everything from how users perform tasks on their mobile devices while walking on a treadmill to how users navigate mobile maps, to mobile restaurant selection, as well as the niche-specific nature of many of these studies, the results of which may not be transferable to other contexts. ${ }^{12}$

When looking at mobile usability studies specifically within the higher education sector, a field more closely related to libraries, research focuses primarily on the use of mobile phones for enhancing student learning through specific activities or sites. ${ }^{13}$ Less research examines how mobile portal or university homepages are used. One exception is the Iowa Course Online (ICON) Mobile Device Survey, which was administered in 2010 and asked students what aspects of ICON (a course management system) they used on their mobile devices. ${ }^{14}$ Students were frequent users of this site; three-quarters of respondents used the site at least 1-3 times per week. The top three selected tasks were grades, "content" (a category including PDFs and Microsoft Word documents), and schedules. As defined by Kaikkonen, users' top tasks included a mix of "passive" content that require no additional interaction (e.g., grades, weather) and "active" content, which requires further searching, reading, or location-specific information from the user (e.g., searching in web browsers, mapping, or looking through PDFs). ${ }^{15}$ The combination of passive and active content more closely matches the types of tasks potentially required by mobile library website users. 
Research on library mobile site use or usability primarily has focused on users' speculations about what they might like from a mobile library site before the site was constructed, or on a handful of users' experiences navigating an existing site while accomplishing researcher-assigned tasks. ${ }^{16}$ No known research exists that demonstrates what tasks users actually perform on an existing mobile library website in real-time. For example, focus groups conducted in 2009 at Kent State University library before the creation of their mobile site led to the conclusion that "students want the site for 'quick research' not to 'sit down and write a term paper on my phone,"' and that students did not want as many research choices, such as all of the databases the library subscribes to, made available on their mobile device (or perhaps even on the full website). ${ }^{17}$ A survey at the Open University in the United Kingdom given prior to deployment of the mobile site extrapolated that students would want to access library hours, a map of the library, contact information, the library catalog and their borrowing record from their mobile device. ${ }^{18}$ In addition, a survey of the student body at Utah State University in 2011 intended to help inform their mobile site design found that students might want to access the mobile catalog, retrieve articles and reserve study rooms. ${ }^{19}$ These results helped determine the future development of these academic library mobile websites and were interpreted to demonstrate that particular tasks might be better suited for the mobile environment. However, they also demonstrate that student users might want to engage in a variety of both active and passive tasks, such as searching the library catalog and checking the library's hours.

As part of a growing recognition that it is time to reevaluate mobile library sites, Bohyun Kim, reviewed eight library mobile sites, and presented her analysis at the American Library Association Annual Conference in 2012. ${ }^{20}$ Kim compared screenshots of 2010 and 2012 homepages and found a greater emphasis on search in the 2012 versions. Kim also highlighted constraints and assumptions that are no longer true in the mobile environment, such as mobile devices' slow networks, a focus on information on the go, and mobile sites with fewer features and content. Kim's analysis signals a shift in how libraries, as well as the broader mobile environment, are envisioning the content they provide on their mobile sites.

Because websites designed for the mobile context are still relatively new, an important part of this shift in the design of library's mobile sites should include an investigation into what types of tasks users are actually performing on these sites. Using web analytics software, we are able to learn which mobile webpages are the most visited on OSU's mobile site, and we know the path users took from the first hit to when they exited the site. However, what we do not know is what the user's intention is in visiting the site, what types of searches they enter, or if these users are able to accomplish their search goals. The objectives of this study were to gather a list of tasks users attempt to accomplish when visiting the library mobile site and to understand the difficulties users encounter when they try to access information on the OSU's mobile site. A more in-depth understanding of how our mobile website is used will help us to provide an improved interface, especially as we work on a site redesign. 


\section{METHODS}

This study used an online survey instrument to gain a better understanding of what tasks mobile site visitors are trying to perform when they visit our library's mobile site, to discover whether they were able to accomplish their task, and any other general impressions, suggestions, or feedback these users had about our mobile library site. This survey (approved by OSU's institutional review board) was available on the Qualtrics survey platform for twelve-weeks from November 2012 to January 2013. The survey was accessible via a link on the mobile version of our library's homepage, meaning that only users who used the mobile-optimized version of our website had access to the survey. The survey was open to anyone who used the library's mobile website, not just OSU affiliates. The survey was completed by 115 participants. A $\$ 2$ gift certificate to a coffee shop was distributed to participants upon completion of the survey.

Because mobile site use can cover a complex range of scenarios, and because we were more interested in learning about what this range of scenarios was for our mobile site, we did not use a closed-task scenario with preset tasks. We asked real users who were currently browsing the mobile site to choose from a list of tasks that best described what they were searching for on the library's mobile site (there were also open-ended questions and options). If they were looking for a book or planned to conduct research on a topic, we used display logic in our survey to further probe their answer and ask about the parameters of their search. If they indicated they had previously used the mobile site to search for books or other research materials, we used the same method used with the book search to ask if they were able to find these materials. If they were looking for articles, we then asked if they read the articles on their mobile device. In addition, we asked if there was anything they wished they could do on the site and for any other general feedback on the mobile site. Finally, we collected some demographic information about the participants: their OSU affiliation and the frequency with which they use the library's mobile site.

The survey data was analyzed using Qualtrics' cross-tab functionality and Microsoft Excel to observe trends and potential differences by user groups. Open-ended responses were examined for common themes. To help provide some counterbalance to our survey data, a combination of Urchin and Google Analytics statistics were analyzed for two of the months the survey was available. Urchin statistics were gathered for the mobile version of the website, and Google Analytics statistics of our Drupal-based pages were gathered for mobile users of the full version of the library's website. We tabulated average daily visitors, specific page views, and the type of browser used with these analytical tools.

\section{FINDINGS}

\section{Online Survey-Closed-Ended Questions}

An advantage of administering a survey versus simply using web analytics to assess a mobile site is that more granular information, such as demographics, can be gathered. Of the 115 online survey respondents, 74 identified themselves as undergraduate students, 19 were graduate 
students, 8 were faculty members, 3 were community members, 2 were alumni, 2 were staff members, and 1 chose the "other" field and self-identified as a parent (see figure 1). Not all respondents answered every question. Because undergraduates make up the overwhelming majority of the campus body, it makes sense that 64 percent of respondents identified themselves as undergraduates. However, the demographic responses also illustrate that multiple user groups access the library's mobile site.

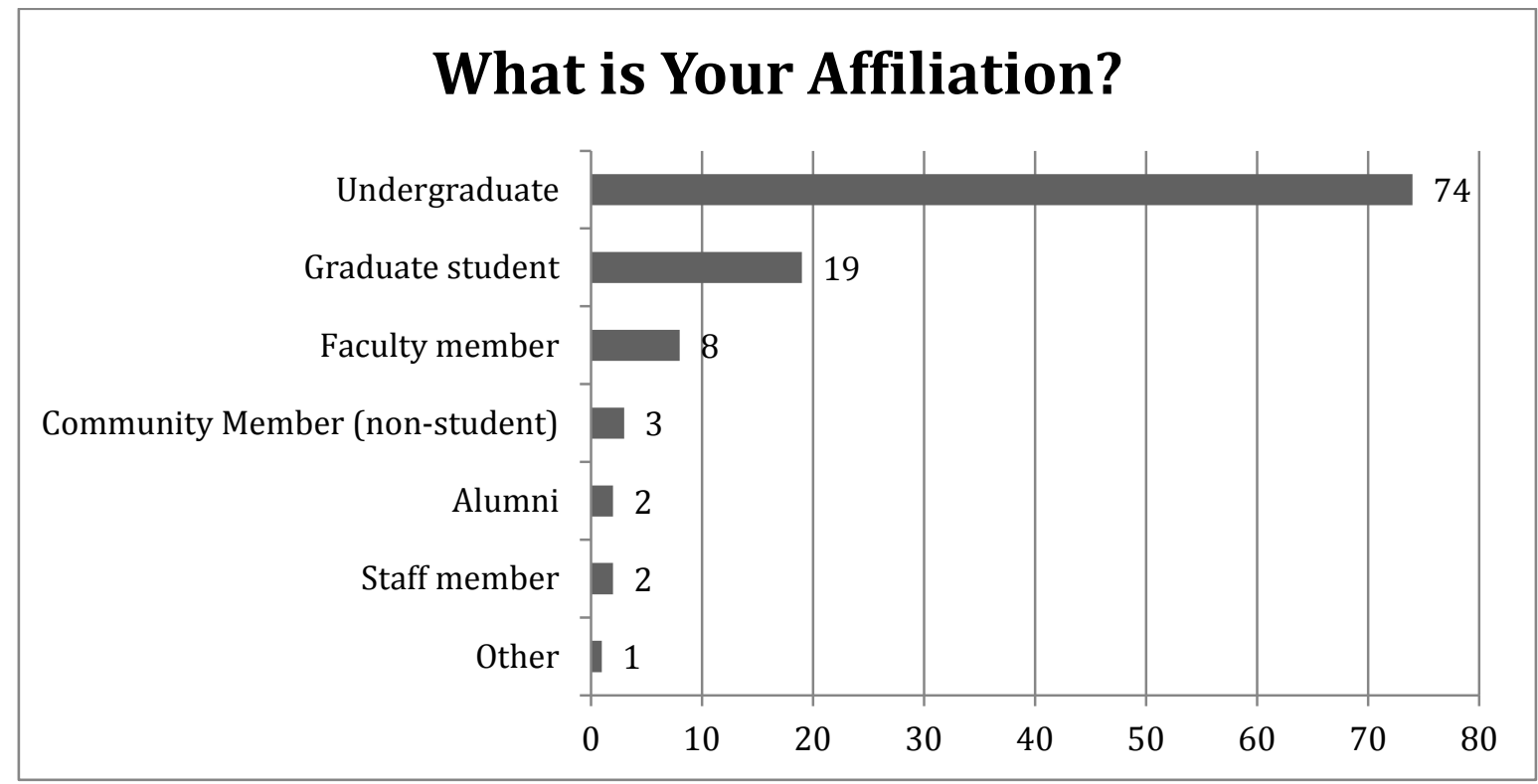

Figure 1. Demographic distribution of survey respondents $(N=109)$.

The survey participants were asked how often they had previously used the library's mobile site. Sixty-nine respondents (60 percent) were accessing the site for the first time. No respondents used the mobile site daily, 1 respondent visited 2-3 times per week, 5 respondents (4 percent) visited once a week, 11 respondents (9.5 percent) visited 2-3 times per month, 7 respondents (6 percent) visited once a month, and 16 (14 percent) visited less than once a month (see figure 2). The majority of respondents had not previously used the library's mobile site. One possible reason for this is that the data was collected primarily during fall term, a time when there are many new students on campus. An alternative explanation is that people who use the mobile site often are highly task-oriented and did not want to be distracted by taking a survey. The fact that the majority of respondents had not previously used the library's mobile site affected responses to later questions in the survey, which asked participants to remember previous experiences and satisfaction with the site. 


\section{How Often Do You Use the Library's Mobile Site?}

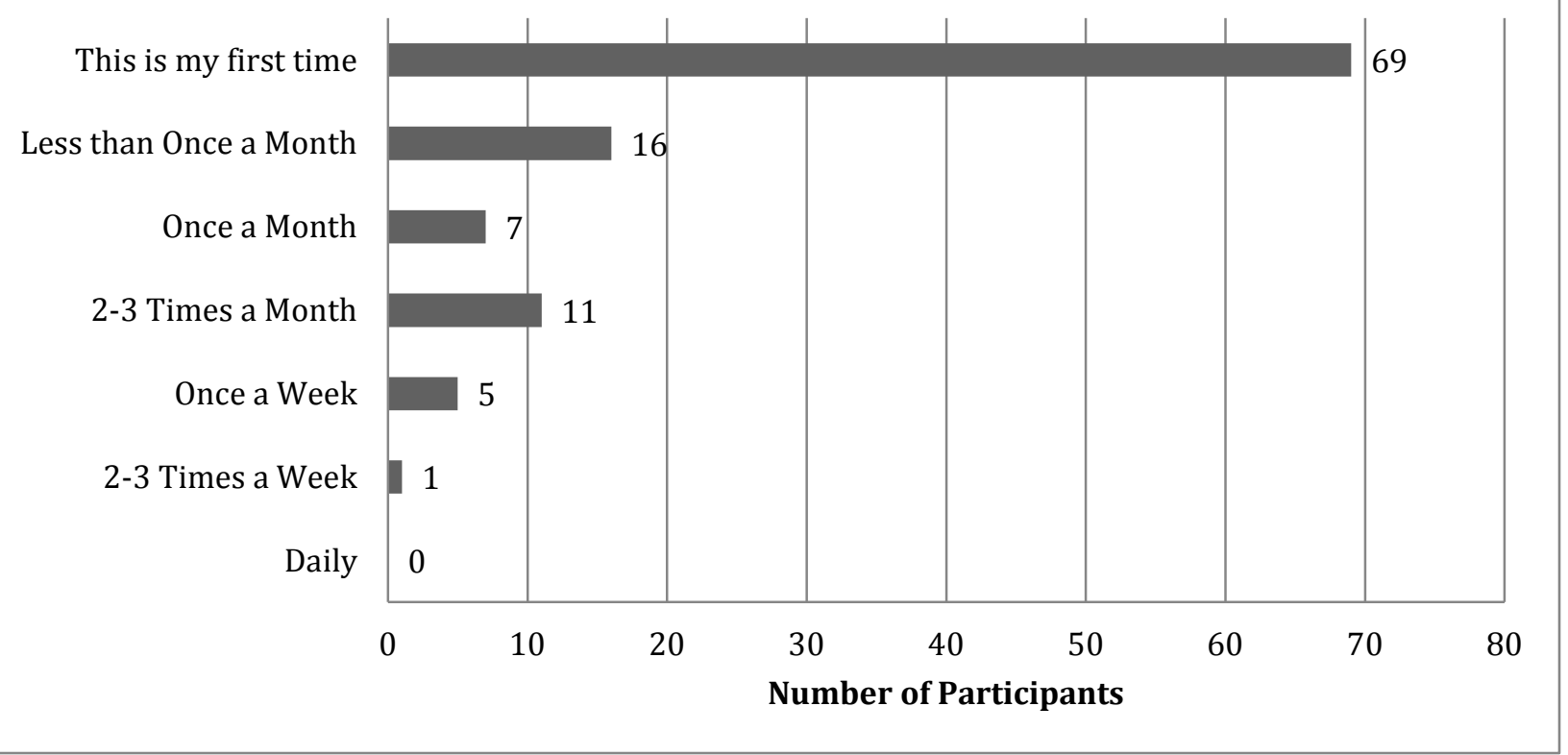

Figure 2. Frequency with which survey respondents used the library's mobile site $(N=109)$.

One of our main research goals was to determine our users' intention for visiting the library's mobile site. Respondents could choose as many items as were applicable from a list of reasons for visiting the library's mobile site; as a result, the data is presented as the percent of total responses. Respondents could also choose "something else" and enter additional reasons for visiting the mobile site. These "other" reasons were grouped and the groupings are reported in the list of reasons for visiting the site. The top reason respondents visited the site was to view the library's hours (47 percent). The next two most frequent reasons for visiting the site were research related, with 25 percent intending to look for a book and 21 percent intending to do research on a topic. The fourth and fifth most common choices were associated with using the library building, with 13 percent looking for study room reservations and 10 percent looking for the availability of computers in the library. Because the library's current mobile site has been optimized for tasks perceived to be most important for mobile users, and because some of the features available via the full-site version of our ILS (integrated library system) are not available via the library's mobile site, not all of the tasks respondents wanted to accomplish on the mobile site were actually available on the mobile site. These items include study room reservations (13 percent of responses); "My Account" features, such as the ability to check due dates, make renewals, and place holds ( 6 percent of responses); and interlibrary loan (1 percent of responses). Finally, some features that had been considered ideal for the mobile context because of their location-sensitive, time-saving, or hedonic functionality - such as looking for directions (1 percent of responses), finding a quick way to contact a librarian with a question ( 2 percent of responses), and viewing 
the webcam for the coffee shop line ( 3 percent of responses)-were rarely selected as a reason for visiting the mobile site (see figure 3).

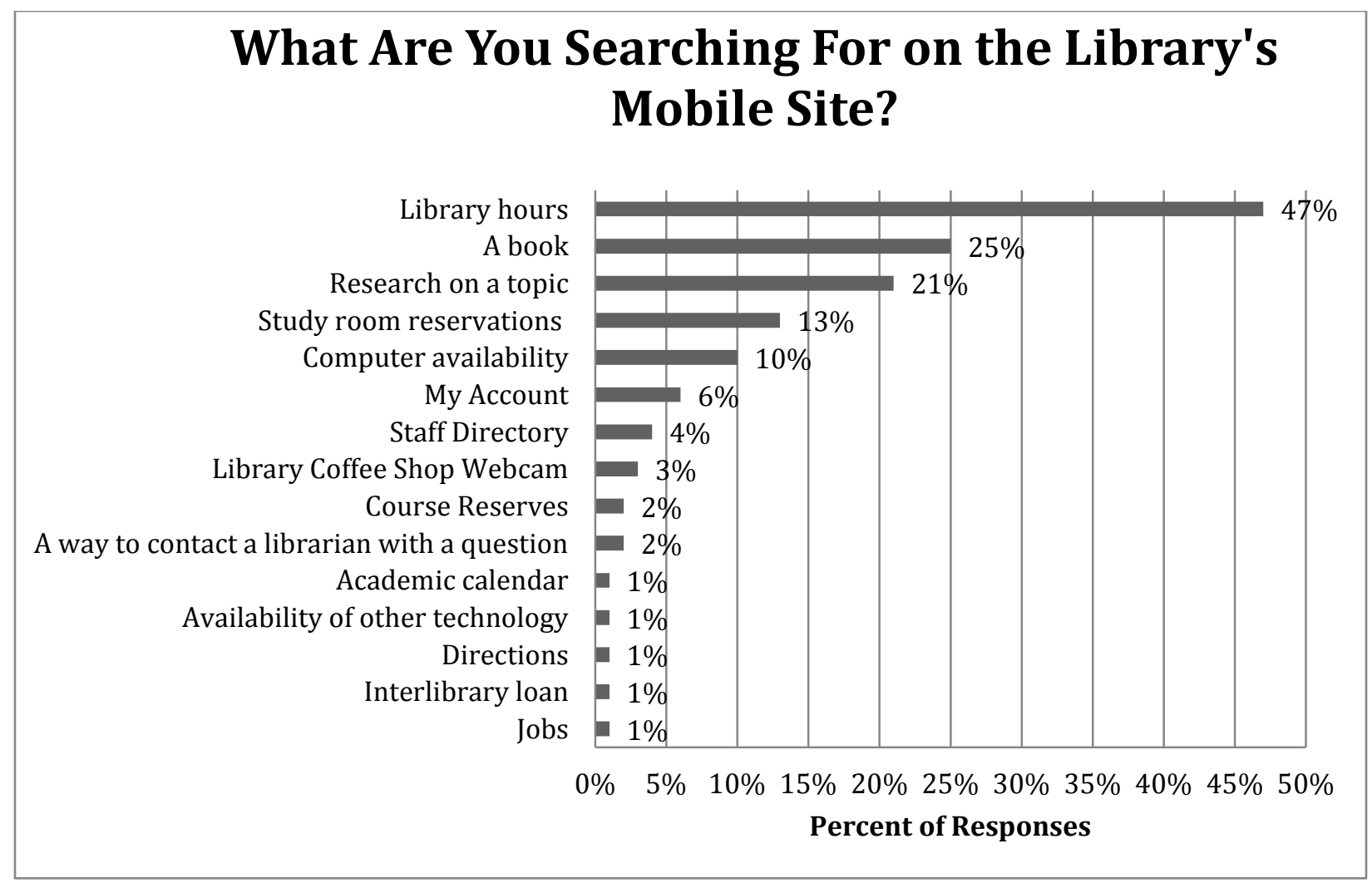

Figure 3. Respondents' reasons for visiting the library's mobile site by percent of responses. Respondents could choose more than one response.

To determine if different user groups approach the library's mobile site differently, we compared the reasons for visiting the mobile site across user groups. When looking at the top five reasons respondents visited the mobile site, only a few differences appeared based on user group (because of the small sample size, a statistical analysis determining significance cannot be done, but results may indicate avenues for future research). Graduate students were somewhat more likely to visit the library's mobile site to look for research on a topic, as well as to look for study room reservations. However, undergraduate students were more likely than graduate students to be interested in the availability of computers in the library (see table 1). 


\begin{tabular}{|l|c|c|c|c|c|c|}
\hline \multicolumn{2}{|c|}{ What Are You Searching For During This Visit to the Library Mobile Site? } \\
\hline & $\begin{array}{c}\text { Library } \\
\text { hours }\end{array}$ & $\begin{array}{c}\text { A } \\
\text { book }\end{array}$ & $\begin{array}{c}\text { Research } \\
\text { on a } \\
\text { topic }\end{array}$ & $\begin{array}{c}\text { Study room } \\
\text { reservations }\end{array}$ & $\begin{array}{c}\text { Computer } \\
\text { availability }\end{array}$ & $n$ \\
\hline Undergraduate & 48.7 & 21.6 & 14.9 & 14.9 & 12.2 & 74 \\
\hline Graduate student & 47.4 & 31.6 & 31.6 & 21.1 & 5.3 & 19 \\
\hline Faculty member & 12.5 & 25 & 37.5 & 0 & 0 & 8 \\
\hline Community member & 100 & 33.3 & 33.3 & 0 & 0 & 3 \\
\hline Staff member & 0 & 0 & 50 & 0 & 0 & 2 \\
\hline Alumni & 50 & 50 & 0 & 0 & 0 & 2 \\
\hline Other & 0 & 0 & 0 & 0 & 0 & 1 \\
\hline
\end{tabular}

Table 1. Percentage of respondents' reasons for visiting the library's mobile site by user group for the top five most-selected tasks. (Respondents could choose more than one response.)

Because the online survey was available over a twelve-week period, which included portions of fall term, winter break, and winter term, we could look at a breakdown of use by time of term. Specifically, we wanted to see if there was a difference in use during the middle of the term versus finals week and intersession. During the latter period, we anticipated users would not be using the library's mobile site for research purposes; however, when comparing these two different usage periods for the top five reasons respondents visited the site, we found respondents' tasks tended to be quite similar regardless of whether or not the term was in session. The only two differences were (1) during intersession respondents tended to be more likely to search for a book using the mobile site and (2) during the term, more respondents were looking for a way to make study room reservations. While the high number of respondents looking for library hours dominates these results, it does appear that respondents were still using the mobile site to conduct researchrelated tasks even during intersession (see figure 4). 


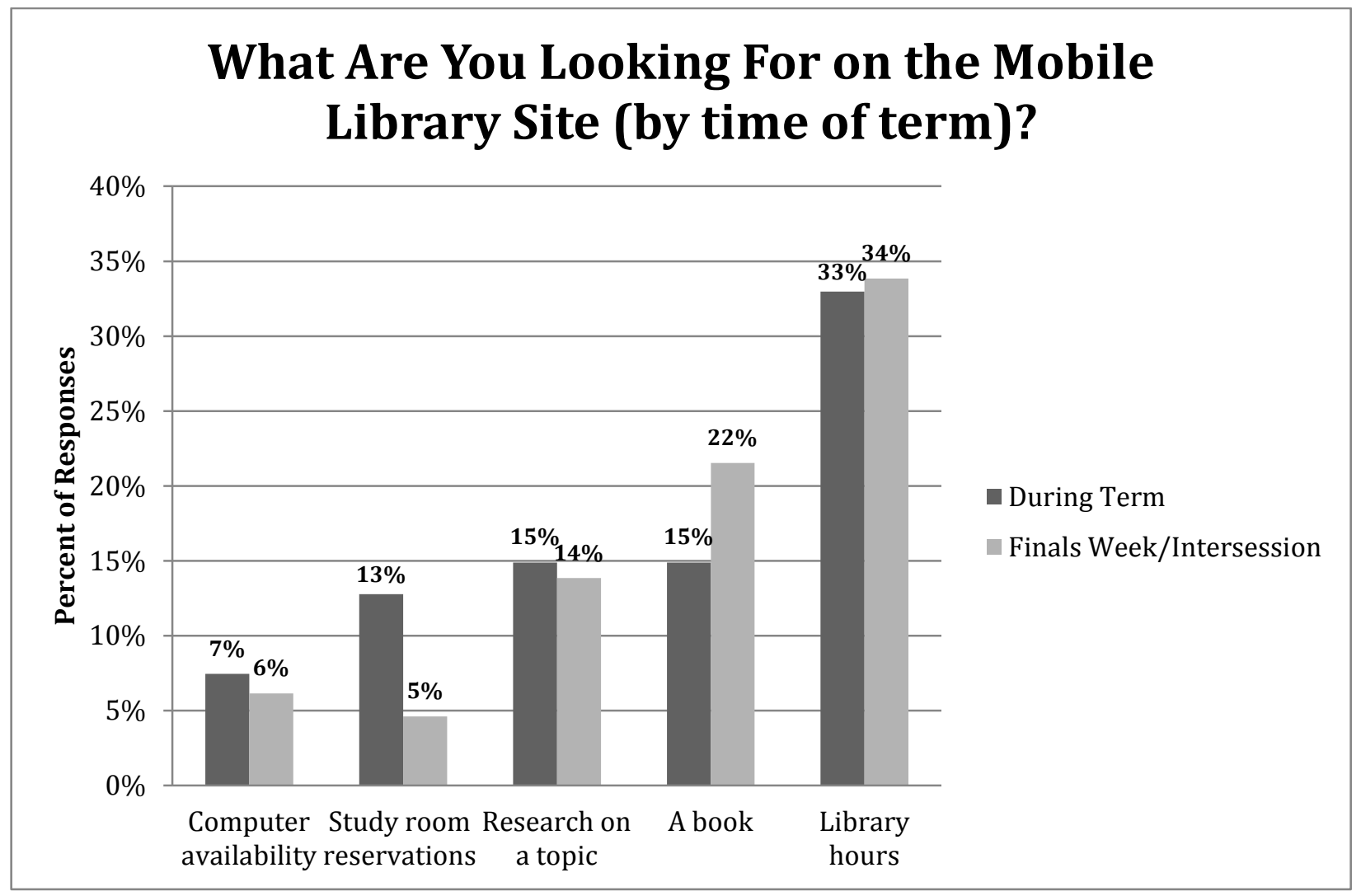

Figure 4. Percentage of respondents' reasons for visiting the library's mobile site by during term vs. intersession for the top five most-selected tasks. Respondents could choose more than one response.

\section{Online Survey-Open-Ended Questions}

As described earlier, the second and third most frequently cited reasons for visiting the library's mobile site were research related: looking for a book and doing research on a topic. Survey participants indicating they had come to the site looking for a book were prompted to enter the search they intended to use. Of the twenty-eight respondents who indicated they were looking for a book, twenty-five provided the search words they planned to use (see table 2). Respondents reported a wide range of search types, from known-item titles or authors such as Moby Dick or Ian Fleming, to broad topic areas such as Women Studies, to focused keywords like "high performance computing." All of these searches fit into the active task category of mobile use. 


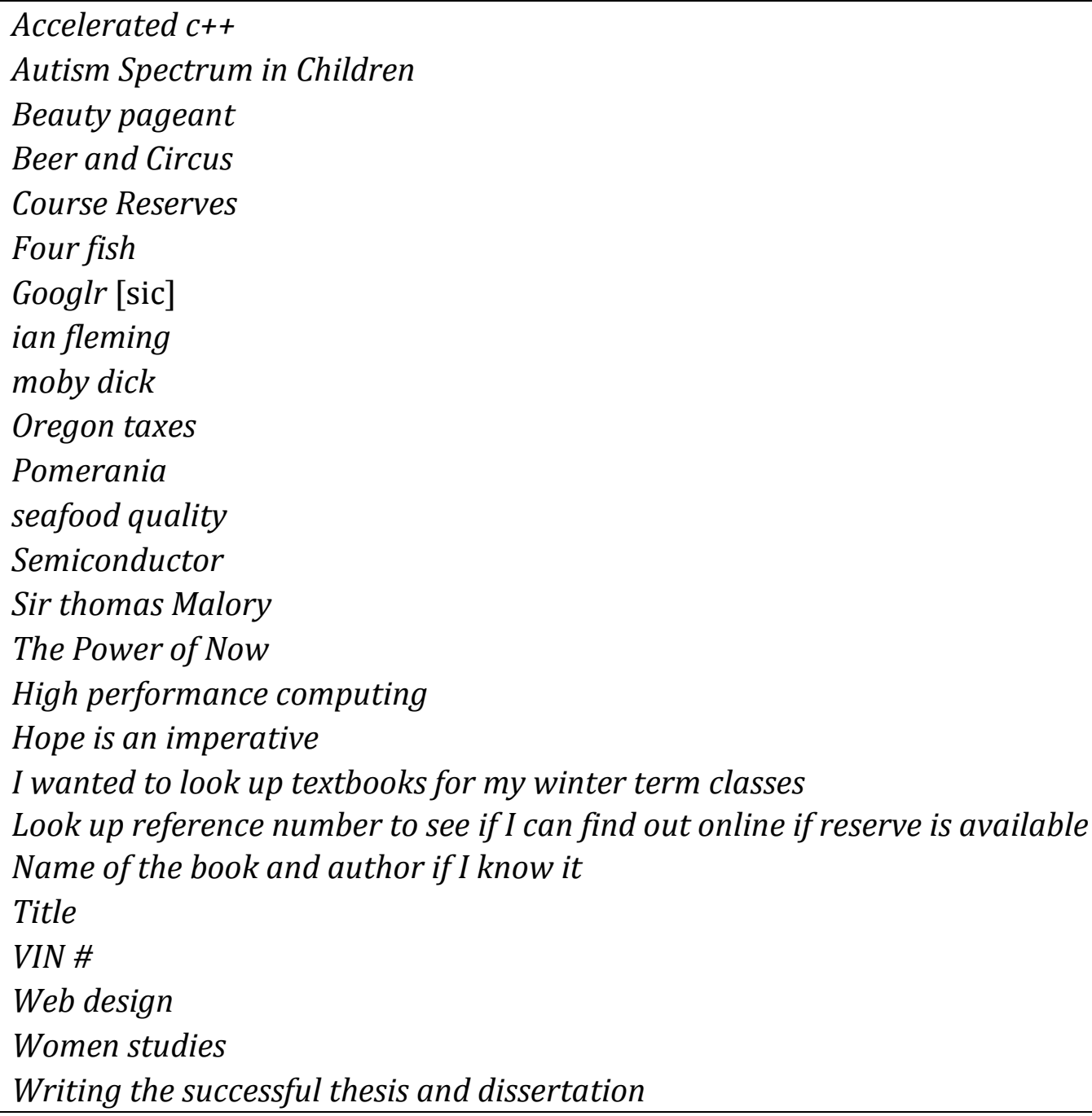

Table 2. Respondents' book searches on their mobile device.

If a survey participant indicated they had come to the site to conduct research on a topic, we prompted them to provide more detailed information about their search. Of the twenty-three respondents who indicated they were conducting research on a topic, twenty provided the search words they planned to use (see table 3). It is apparent from the responses that at least five respondents misunderstood our question, and instead of entering keywords for a search, they entered the databases or search engines they planned to use to conduct their research, such as 1Search (our library's iteration of Serials Solutions' Summon), ERIC, PsycInfo, and perhaps Google; although, when considering the search term Google, it is possible the respondent was going to attempt to conduct research on the Google company itself. The remaining search terms reflect indepth concepts that would either retrieve many results (e.g., procurement and contract processes), or that while retrieving fewer results would give the researcher more than just a single simple document to consult (e.g., ethnobotany Oregon). As with the book searches, these research topics represent more active tasks that move the mobile user beyond the earlier perceptions of mobile use that predicted tasks centered on quick, entertaining, or location-specific information. ${ }^{21}$ 


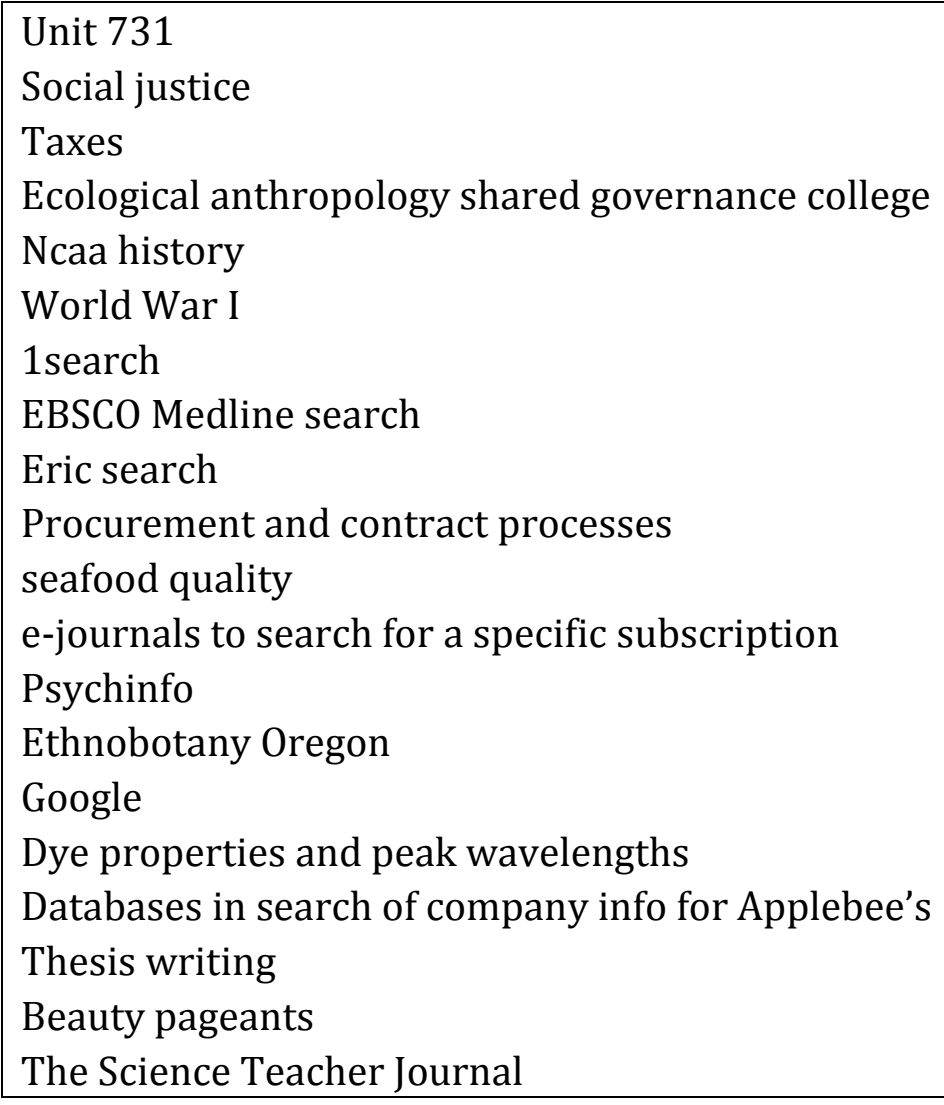

Table 3. Respondents' topic searches for nonbook research sources.

\section{Web Analytics Results}

In addition to collecting survey responses, we monitored our web analytics during the survey period to see how the site usage matched with our survey respondents' stated activities. The mobile version of the site averaged 124 daily visitors between November 5, 2012, and January 5 , 2013. The top three pages viewed were the computer availability map (37 percent), the mobile homepage ( 25 percent) and the research page ( 3 percent). The mobile homepage also displays the library hours. Because mobile users do not just use mobile optimized sites, we also looked at mobile use of the Drupal-designed pages on the full version of our website. Of the top twenty pages viewed, eleven were content pages and nine were navigational pages. Based on page views, the top three content pages were study rooms ( 8 percent), hours (5 percent) and research databases ( 5 percent). The top three navigational pages based on page views were the homepage (40 percent), which also displays the library hours, the Find It page (8 percent), which lists links to content like databases, the catalog, and ejournals, and the In the Library page (7 percent), which provides links to information about things a patron might use in the library, such as study rooms or computers. The web analytics do not exactly mirror the tasks reported by the survey respondents and reflect an even greater emphasis on practical tasks like using a computer or a study room in the library. 
In our research a disconnect appeared between what users actually do on the mobile site, according to Urchin and Google Analytics, and what they would like to do on the site based on information gathered from the participants of our online survey. It became apparent from our survey that our participants were not only attempting simple searches appropriate for a strippeddown mobile-optimized site but were also attempting active tasks, like conducting more complex searches we formerly would have expected them to do only on the full site. We needed a website that no longer restricted the activities our users could do based on our outdated assumptions of their use of our website.

\section{Responsive Design}

As a solution to our problem of how to provide a consistent, nonrestricted experience to all of our users regardless of how they were accessing our site, we turned to the concept of responsive design. Responsive design was conceived as recently as 2010,22 but adoption is growing rapidly because it offers a more scalable solution for designers, allowing them to move away from designing different websites for every platform, and instead designing sites that scale differently in different contexts (for example, an iPhone vs. an iPad). Responsive design is a more dynamic strategy, requiring as web designer Ethan Marcotte states, "fluid grids, flexible images, and media queries." 23 However, Marcotte goes on to argue that responsive design "requires a different way of thinking. Rather than quarantining our content into disparate, device-specific experiences, we can use media queries to progressively enhance our work within different viewing contexts." The following images illustrate the reflow of a responsive design layout for desktop and tablet views.

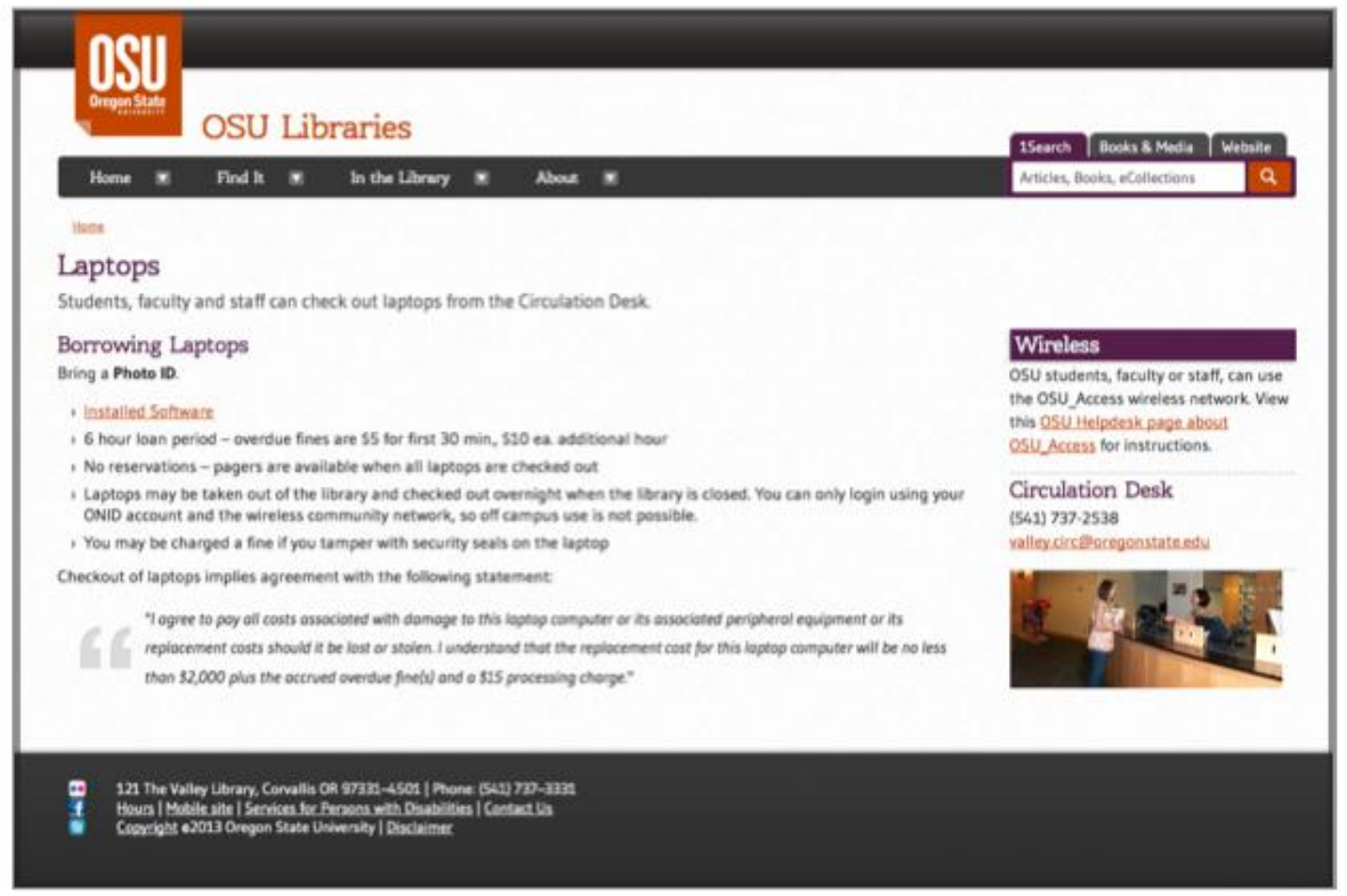

Figure 5. Desktop view of responsive OSU Libraries webpage. 


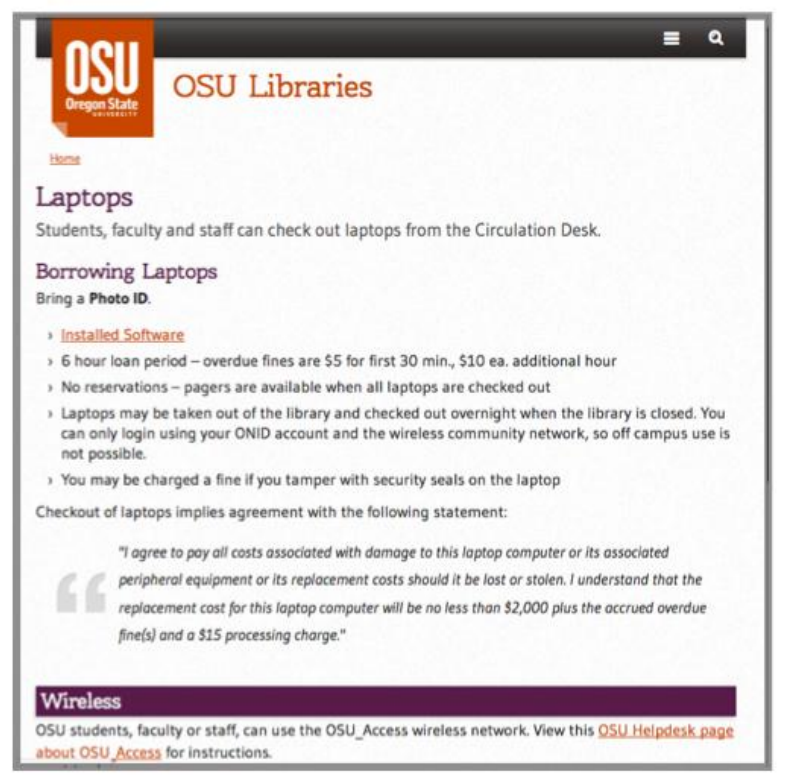

Figure 6. Tablet view of responsive OSU Libraries webpage.

This summer, our web designer redesigned both the full site and mobile site using responsive design. At OSU, we have decided that we will no longer have a separate mobile site. Instead, Drupal responsive design modules and themes allow our site to be viewed optimally, independent of screen size, as "one web." 24 Using a responsive design allowed us to choose a one-column layout for our mobile site and a three column layout for our full site. Using Drupal modules and themes, the three columns from the full site reflow into one column on the mobile device. Menu bars collapse, numerous static pictures become one image box with rotating pictures, and paragraphs are simply linkable titles. These design decisions allow users to perform both active and passive tasks depending on their needs, regardless of context.

Responsive design provides clear advantages for designers, for example, they no longer need to maintain separate versions of low-use pages, such as a directions page. In addition, while responsively designed websites are not automatically accessible, it is simpler for designers to create a single iteration of a site that meets accessibility guidelines, and which can then scale appropriately to other contexts. However, there are also advantages for the user. Responsive design ensures that users will encounter a predictable interface and experience across all of the platforms from which they access the library's website. Moreover, in our local context, we have had a policy of not providing links to websites not optimized for mobile devices, such as databases, from our mobile site. As we switched to a responsively designed site, we moved away from this policy, thereby providing more research choices to our mobile users.

There are also some drawbacks to using responsive design in our context. Some might consider linking out to resources not optimized for mobile devices a drawback rather than an advantage. In addition, our redesign only involved applying responsive principles to our library sites that are developed in Drupal. Sites such as the study room reservation system, My Account, and the 
library's catalog draw upon other vendors' tools, and therefore are not under our design control. However, access to these sites will no longer be circumscribed for mobile users, but may involve less intuitive navigation depending on their device.

\section{CONCLUSION}

Our goal in this study was to gain a more in-depth understanding of how our mobile website is used to guide a redesign of our mobile interface. As a result of examining current trends in web design and development, through analysis of the data we collected that demonstrated not only what our users currently do on our mobile site but also what they intend to do and what gaps they perceive in our service, we have chosen to integrate our full and mobile sites into "one web" through the use of responsive design. Gathering qualitative information from our mobile site users has provided us with more realistic tasks that we can use in further usability testing. Finally, we are again reminded of the continual evolution of our users' needs and the expanding possibilities that are available as information becomes increasingly mobile.

\section{REFERENCES}

1. Jeff Clabaugh, "BlackBerry U.S. Market Share Falls to 5.4 percent; Google's Android Remains on Top," Washington Business Journal, April 4, 2013, http://www.bizjournals.com/washington/news/2013/04/04/blackberry-us-market-sharefalls-to.html.

2. Laurie Bridges, Hannah Gascho Rempel, and Kimberly Griggs, "Making the Case for a Mobile Library Web Site," Reference Services Review 38, no. 2 (2010): 309-20, doi: 10.1108/00907321011045061.

3. Anne Kaikkonen, "Full or Tailored Mobile Web-Where and How Do People Browse on Their Mobiles?" in Proceedings of the International Conference on Mobile Technology, Applications, and Systems, Mobility '08 (New York: ACM, 2008), 28:1-28:8, doi: 10.1145/1506270.1506307.

4. Jakob Nielsen, “Mobile Usability Update (Jakob Nielsen's Alertbox)," September 26, 2011, http://www.useit.com/alertbox/mobile-usability.html.

5. "Feature Phones Comprise Overwhelming Majority of Mobile Phone Sales in Q2 2009," NPD Group, 2009, https://www.npd.com/wps/portal/npd/us/news/press-releases/pr 090819/.

6. Kim Griggs, Laurie M. Bridges, and Hannah Gascho Rempel, "Library/Mobile: Tips on Designing and Developing Mobile Web Sites," Code4Lib Journal 8 (November 11, 2009), http://journal.code4lib.org/articles/2055.

7. Alan Aldrich, "Universities and Libraries Move to the Mobile Web," Educause Review Online, June 24, 2010, http://www.educause.edu/ero/article/universities-and-libraries-movemobile-web. 
8. Nielsen, "Mobile Usability Update (Jakob Nielsen's Alertbox)."

9. Jakob Nielsen, “Mobile Site vs. Full Site (Jakob Nielsen's Alertbox)," April 10, 2012, http://www.useit.com/alertbox/mobile-vs-full-sites.html.

10. Keren Mills, M-Libraries: Information Use on the Move (Cambridge, UK: Arcadia Programme, 2009), http://www.dspace.cam.ac.uk/handle/1810/221923; Bridges, Rempel, and Griggs, "Making the Case for a Mobile Library Web Site."

11. Anne Kaikkonen, "Full or Tailored Mobile Web?"

12. Constantinos K. Coursaris and Dan J. Kim, "A Meta-Analytical Review of Empirical Mobile Usability Studies," Journal of Usability Studies 6, no. 3 (May 2011): 117-71.

13. Emrah Baki Basoglu and Omur Akdemir, "A Comparison of Undergraduate Students' English Vocabulary Learning: Using Mobile Phones and Flash Cards," Turkish Online Journal of Educational Technology-TOJET 9, no. 3 (July 1, 2010): 1-7; Suzan Duygu Eristi et al., "The Use of Mobile Technologies in Multimedia-Supported Learning Environments," Turkish Online Journal of Distance Education 12, no. 3 (July 1, 2011): 130-41; Stephanie Cobb et al., "Using Mobile Phones to Increase Classroom Interaction," Journal of Educational Multimedia and Hypermedia 19, no. 2 (April 1, 2010): 147-57; Shelley Kinash, Jeffrey Brand, and Trishita Mathew, "Challenging Mobile Learning Discourse Through Research: Student Perceptions of 'Blackboard Mobile Learn' and 'iPads,'” Australasian Journal of Educational Technology 28, no. 4 (January 1, 2012): 639-55.

14. University of Iowa, ICON Mobile Device Survey, n.d., https://icon.uiowa.edu/support/statistics/ICON percent20Mobile percent20Device percent20Survey.pdf.

15. Anne Kaikkonen, "Full or Tailored Mobile Web?"

16. Kimberly D. Pendell and Michael S. Bowman, "Usability Study of a Library's Mobile Website: An Example from Portland State University," Information Technology \& Libraries 31, no. 2 (2012): 45-62, doi: 10.6017/ital.v21i2.1913.

17. Jamie Seeholzer and Joseph Salem, "Library on the Go: A Focus Group Study of the Mobile Web and the Academic Library," College \& Research Libraries 72, no. 1 (January 2011): 9-20.

18. Mills, M-Libraries.

19. Angela Dresselhaus and Flora Shrode, "Mobile Technologies \& Academics: Do Students Use Mobile Technologies in Their Academic Lives and Are Librarians Ready to Meet This Challenge?" Information Technology \& Libraries 31, no. 2 (2012): 82-101, doi: 10.6017/ital.v31i2.2166. 
20. Bohyun Kim, “It's Time to Look at Your Library's Mobile Website Again!” (presented at the American Library Association Annual Conference, Anaheim, CA, June 24, 2012), http://www.slideshare.net/bohyunkim/its-time-to-look-at-your-librarys-mobile-websiteagain.

21. Bridges, Rempel, and Griggs, "Making the Case for a Mobile Library Web Site."

22. Ethan Marcotte, "Responsive Web Design," A List Apart, May 25, 2010, http://alistapart.com/article/responsive-web-design.

23. Ibid.

24. Jeff Burnz, “Responsive Design,” Drupal, February 14, 2013, http://drupal.org/node/1322126. 